\title{
Platinum-enhanced graphitisation in sandwich structures of silicon carbide and borosilicate glass
}

\author{
A. Hähnel, J. Woltersdorf* \\ Max-Planck-Institut für Mikrostrukturphysik, D-06120 Halle, Weinberg 2, Germany
}

Received 3 August 2003; accepted 7 November 2003

\begin{abstract}
Heat-treated sandwich structures of borosilicate glass and $6 \mathrm{H}-\mathrm{SiC}$ single crystals (with and without platinum pre-coating) were used as model composites to study the reaction kinetics of the interlayer formation in the system $\mathrm{Si}-\mathrm{C}-\mathrm{O}$. High resolution and analytical electron microscopical methods revealed a complex interlayer system, mainly consisting of different phases of carbon and silica. A distinct increase in the degree of graphitisation and texturisation of the reaction layer was observed after Pt deposition on the silicon carbide surface, which is attributed to the graphitising effect of both platinum and platinum silicide.
\end{abstract}

(C) 2003 Elsevier B.V. All rights reserved.

Keywords: Thin films; Composite materials; Silicon carbide; Platinum coatings; Metal-mediated graphitisation; High-resolution microscopy; Analytical electron microscopy

\section{Introduction}

The high potential of continuous fibre-reinforced ceramics and glasses is based upon their damage tolerant and quasi-ductile behaviour. However, this can only be achieved by appropriately activating energy-dissipative processes like crack shielding and deflection, debonding and pull-out, which are controlled by the bond strength and sliding resistance in the interlayer regions between fibre and matrix [1-3]. Thus, the optimisation of the mechanical properties of composites with brittle matrices is equivalent to the tailoring of their interlayers.

As we have demonstrated in previous studies [3,5], controlling of the mechanical properties of silicon carbide fibre-reinforced glasses and ceramics is possible by special texturised carbon layers with graphitic basal planes parallely aligned to the fibre/matrix interface. Within the hexagonal basal planes, the planar, trigonal $\mathrm{sp}^{2}$-hybridisation of the $\mathrm{C}$-atoms yields strong $\sigma$-bonds, whereas perpendicular to these basal planes the electrons of the $2 \mathrm{p}_{z}$-orbitals are forming only weak $\pi$-bonds. The resulting anisotropy of properties of graphitic layers allows to control debonding and pull-out $[4,5]$.

\footnotetext{
* Corresponding author. Tel.: +49-345-558-2922; fax: +49-345-551-1223.

E-mail address: wolt@mpi-halle.de (J. Woltersdorf).
}

As an important precondition for the composite optimisation, the processing of the composites must result in an appropriate structure where matrix and fibres being located in correspondence with the loading geometry of the component. For this joining of the composite partners, processing methods as, e.g. chemical vapour infiltration, pyrolysis of preceramic polymers or hot-pressing are used. During these processes, fibre/matrix interlayers are formed by chemical reactions with very complex structures, depending on the specific reaction conditions such as, e.g. temperature, composition of matrix and fibre, and partial pressures of the gaseous species.

In silicon carbide fibre-reinforced glasses, carbon-rich interlayers are mainly formed by reactions between silicon carbide and oxygen [6-13]. Based on the observed interlayer phenomena, we could explain the layer forming processes by use of volatility diagrams of the system $\mathrm{Si}-\mathrm{C}-\mathrm{O}$ revealing that variations in the pressures of $\mathrm{O}_{2}, \mathrm{SiO}$ and $\mathrm{CO}$ are responsible for the occurrence of various phases (carbon, carbon/silica mixtures, silica) between fibre and matrix [14-16]. Thus, we could develop a four-step model of the layer formation [15]. Among the observed phases there is only a marginal portion of textured carbon permitting a controlled pull-out. For enlarging this part of graphitic carbon being parallel aligned to the fibre surface, the mechanism of its formation has to be adjusted. However, on the conventional way comprising oxidation processes this is coupled with an intense formation of pores. An alternative route should be 
opened up by the reaction of $\mathrm{SiC}$ with a transition metal, which does not form carbides but catalyses the graphitisation. The catalytic graphitisation by metals has been widely investigated in the last 40 years [17-26]. In spite of this, to the best of our knowledge, there has been no application of the catalytic graphitisation on interlayers in $\mathrm{SiC}$ composites so far.

The present paper describes results of new investigations of the reaction kinetics in interlayers between single crystal silicon carbide of the $6 \mathrm{H}$ polytype and borosilicate glass. The studies on these model composites reveal details of both, the carbon formation and the effect of platinum on the graphitisation in the interlayer. Structure and chemistry of the reaction layers were studied down to the atomic scale by use of high-resolution transmission electron microscopy (HREM) and spectroscopic techniques including energy dispersive X-ray (EDX) spectroscopy and electron energy loss spectroscopy (EELS) with special respect to the fine structure near the ionisation edge.

\section{Experimental details}

For the microstructure investigations we used electron diffraction techniques and HREM, carried out in a Philips CM 20 FEG (field emission gun) microscope, operating at $200 \mathrm{keV}$ with a point-to-point resolution of $0.24 \mathrm{~nm}$ and equipped with both, a Gatan imaging filter (GIF 200) and an EDX detector enabling the detection of light elements (IDFix-system, SAMx-Germany). So, EDX analysis and EELS with particular emphasis on the energy loss near edge structures (ELNES) could be used to characterise the nanochemistry of the reaction layers. EELS was performed with a microscope working in the scanning transmission mode (STEM), whereas the half width of the zero loss peak was about $0.8-1.2 \mathrm{eV}$. Series of electron energy loss spectra were recorded by digitally scanning a STEM probe of about $2 \mathrm{~nm}$ in diameter across the reaction zones using the Gatan Digiscan model 688. To minimise contamination effects, a cooling specimen holder was used.

Sandwich structures have been made by merging $\mathrm{HF}$-cleaned single crystals of $6 \mathrm{H}-\mathrm{SiC}$ and plates of borosilicate glass (Fiolax ${ }^{\circledR}$ Schott Glaswerke, Mainz, Germany) [27]. The sandwich size was typically $10 \mathrm{~mm} \times 10 \mathrm{~mm} \times$ $4.4 \mathrm{~mm}$, containing SiC-crystal slides $(3 \mathrm{~mm} \times 3 \mathrm{~mm} \times$ $0.38 \mathrm{~mm}$ ) made from wafers, produced by the modified Lely technique (SiCrystal AG, Eschenfelden, Germany) with the polished wafer surfaces being C-terminated ( $\left.\begin{array}{llll}0 & 0 & 0 & \overline{1}\end{array}\right)$. For producing the sandwiches, glass plates were stacked below and above the SiC single crystals, placed in alumina crucibles, and positioned in a horizontal mullite tube furnace which was equipped with a continuous gas-supplying system and $\mathrm{ZrO}_{2}$ oxygen sensor including a $\mathrm{Pt} / \mathrm{PtRh}$ thermocouple. Using this sensor near the sample, both the partial pressure of oxygen and the temperature could be monitored. All experiments were performed under argon flow $\left(41 \mathrm{~h}^{-1}\right)$.
For the first series of tests, uncoated $6 \mathrm{H}-\mathrm{SiC}$ crystal slides were merged into the borosilicate glass at $1164{ }^{\circ} \mathrm{C}$. The second series of tests comprises sandwich structures made of $6 \mathrm{H}-\mathrm{SiC}$ slides, which were coated with a thin layer of pure platinum of about $5 \mathrm{~nm}$ in thickness before merging into borosilicate glass at $977^{\circ} \mathrm{C}$. By positioning a tantalum foil inside the tube, the partial pressure of oxygen could be reduced to about $10^{-9} \mathrm{~Pa}$ at $1164^{\circ} \mathrm{C}$ or $10^{-13} \mathrm{~Pa}$ at $977^{\circ} \mathrm{C}$ while heating-up the furnace with a ramp of $200 \mathrm{~K} \mathrm{~h}^{-1}$ to the maximum temperature, which was kept for $30 \mathrm{~min}$ before cooling-down again with $200 \mathrm{~K} \mathrm{~h}^{-1}$.

For transmission electron microscopy, specimens have been made using a refined cross-section technique. After fixing the sandwiches with Si-blocks, slides of about $1 \mathrm{~mm}$ in thickness were cut, embedded in wax and divided into small parts, containing the $\mathrm{SiC} /$ glass interface of interest in the centre. After grinding and dimpling, these parts were subsequently glued on $\mathrm{Cu}$ rings. The thinning to electron transparency has been performed by ion milling using the precision ion polishing system PIPS 691 (Gatan Inc.).

\section{Results and discussion}

In both kinds of annealed sandwiches, i.e. with uncoated and with $\mathrm{Pt}$-coated $6 \mathrm{H}-\mathrm{SiC}$, at the interface between the $\mathrm{SiC}$ and the glass partitioned interlayers were formed having a thickness of 100-150 $\mathrm{nm}$ and with the main components (i) $\mathrm{sp}^{2}$-hybridised $\mathrm{C}$ and (ii) $\mathrm{SiO}_{2}$. However, the microstructural and chemical peculiarities of the reaction zone appear rather differently.

\subsection{Interlayers in specimens of uncoated $6 \mathrm{H}-\mathrm{SiC}$ and borosilicate glass}

The features of these interlayers are demonstrated in the HREM image (Fig. 1). The atomic $6 \mathrm{H}$ polytype structure of the silicon carbide can clearly be recognised by alternating bright/dark contrasts (which are induced by a small crystal tilt away from the $\langle 11 \overline{2} 0\rangle$ zone axis $[28,29])$ corresponding to the six-fold stacking of the atomic planes. Each dot represents a $\mathrm{SiC}$ dipole. The interface between the reaction layer and the $\mathrm{SiC}$ shows terraces on the nanometer scale which are adjoining both the inhomogeneously thick amorphous layer of $\mathrm{SiO}_{2}$ (on the left and right of Fig. 1) and an additional, only $5 \mathrm{~nm}$ thick interlayer (in the middle part of Fig. 1), which is adjacent to the amorphous carbon zone (on the top) extending to the glass. The narrow layer consists of turbostratic carbon having the basal planes nearly parallel oriented to the $\left(\begin{array}{llll}0 & 0 & 0 & \overline{1}\end{array}\right)$ plane of the $\mathrm{SiC}$. Thus, even at the high reaction temperature of $1164{ }^{\circ} \mathrm{C}$, the formation of texturised turbostratic carbon is shown to be limited to the region between carbon and silica, whereas the most part of the layer occurs amorphous. This indicates a mechanism of formation of turbostratic carbon via an intermediate step of $\mathrm{CO}$ generation as we have shown in [15,27]. Firstly, 


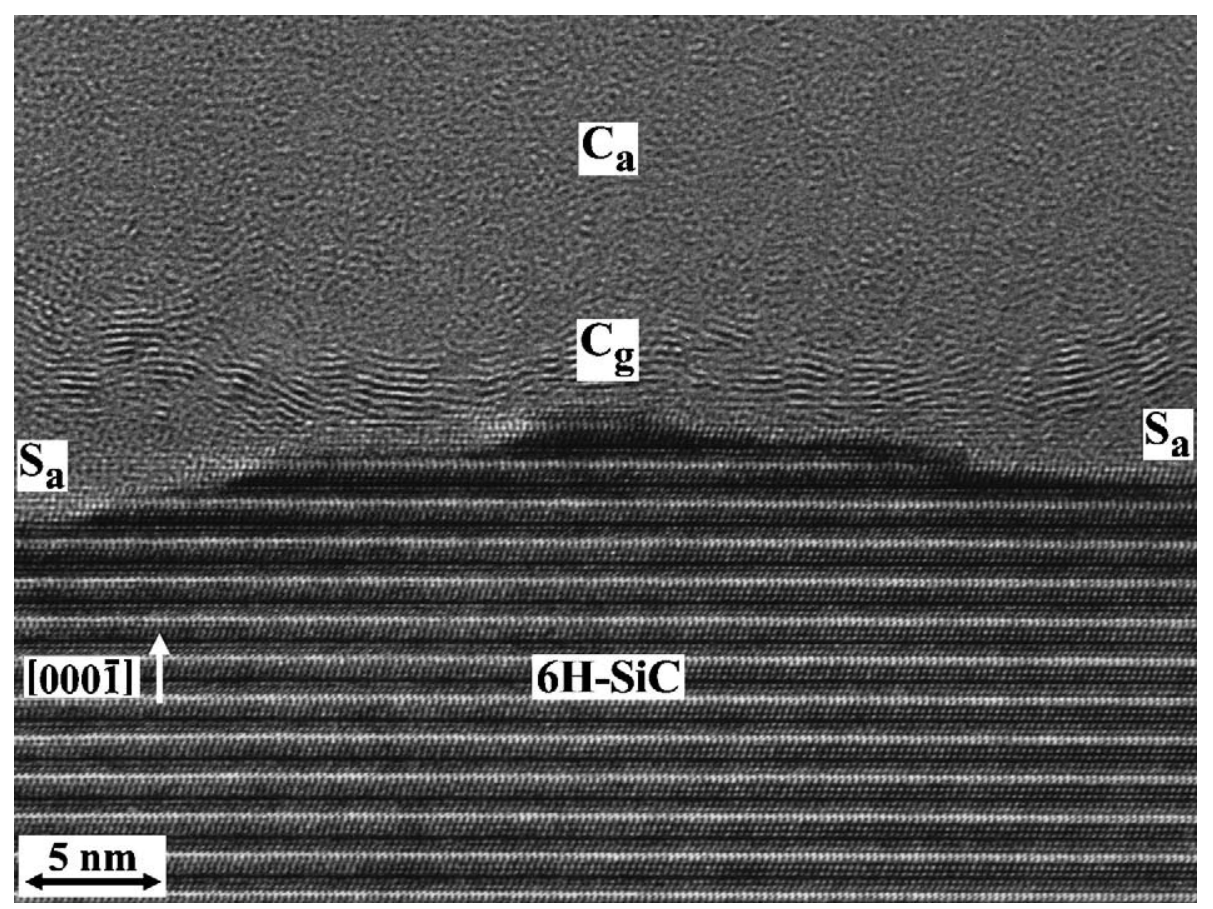

Fig. 1. Details of the interlayer consisting of amorphous carbon $\left(C_{\mathrm{a}}\right)$ and amorphous silica $\left(S_{\mathrm{a}}\right)$ with a lamella of graphitic carbon $\left(C_{\mathrm{g}}\right)$ near to the step-like interface to the $6 \mathrm{H}-\mathrm{SiC}$.

by reduction of $\mathrm{SiO}_{2}$, carbon of the layer is transformed into $\mathrm{CO}$. Then, on cooling from the heat-treatment temperature, carbon re-precipitates turbostratically from the $\mathrm{CO}$ gas according to the Boudouard equilibrium. This is also emphasised by our observation of pores in the region between amorphous carbon and silicate glass with lamellae of graphitic basal planes parallely arranged to the surface of the pores. However, for the required graphitisation of the complete interlayer the total amount of carbon of the layer should be consumed, which would result in a violent formation of pores. Thus, the mechanism of formation of turbostratic carbon via carbon monoxide is inapplicable for the generation of texturised turbostratic interlayers with thicknesses greater than approximately $5 \mathrm{~nm}$.

\subsection{Interlayers in specimens of Pt-coated $6 \mathrm{H}-\mathrm{SiC}$ and borosilicate glass}

In contrast to the findings discussed above, the investigations on structures with $\mathrm{Pt}$-coated $6 \mathrm{H}-\mathrm{SiC}$ show a significant graphitisation of the whole carbon layer.

As can be seen in Fig. 2, lamellae of graphitic basal planes with a distance of $0.344 \mathrm{~nm}$ are generated at the interface to the $\mathrm{SiC}$ as well as within the adjacent reaction layer. In addition, the basal planes of these graphitic lamellae were parallel oriented to the $(000 \overline{6})$ plane of the $6 \mathrm{H}-\mathrm{SiC}$. This corresponds to the diffraction pattern taken from both $\mathrm{SiC}$ and layer, presented in Fig. 3. The diffraction ring of the $(0002)$ graphene sheets of the layer clearly shows brightened arcs being aligned with the $\left[\begin{array}{llll}0 & 0 & 0 & 1\end{array}\right]$ di- rection of $6 \mathrm{H}-\mathrm{SiC}$, indicating a preferred orientation of the graphitic basal planes within the reaction layer. However, as will be shown later, it is not pertinent to refer to a straight catalysing effect of the platinum on the graphitisation. First, the nanochemical peculiarities of the interlayer region shall be considered. Fig. 4 shows EDX-profiles of carbon, oxygen, silicon and platinum acquired along the line which is marked in the STEM bright-field image (on the bottom of Fig. 4). Within the layer, the trends of the signals of carbon as well as of silicon and oxygen indicate high contents of carbon and probably silica. The platinum, which is concentrated in particles, shows correspondingly distinct signal peaks at the particles located within the layer and at the interface to the borosilicate glass.

\subsubsection{Reactions of Pt and SiC}

The platinum-containing particles were formed by the reaction between platinum and silicon carbide. Presumably the first step of this reaction is the significant disintegration of $\mathrm{SiC}$ (Eq. (1)) indicated by the graphitic lamellae penetrating

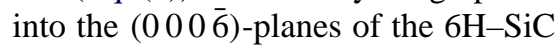

$\mathrm{SiC} \stackrel{\mathrm{Pt}}{\rightarrow} \mathrm{Si}+\mathrm{C}$

as marked by arrows in Fig. 2. By expansion of this graphitic lamellae, some pieces of the silicon carbide are peeled off from the wafer surface and can finally be found within the reaction layer as demonstrated by the silicon carbide flake in the middle part of Fig. 2.

In the next step platinum interacts with silicon which was formed by the $\mathrm{SiC}$ disintegration. Thus, platinum silicide 


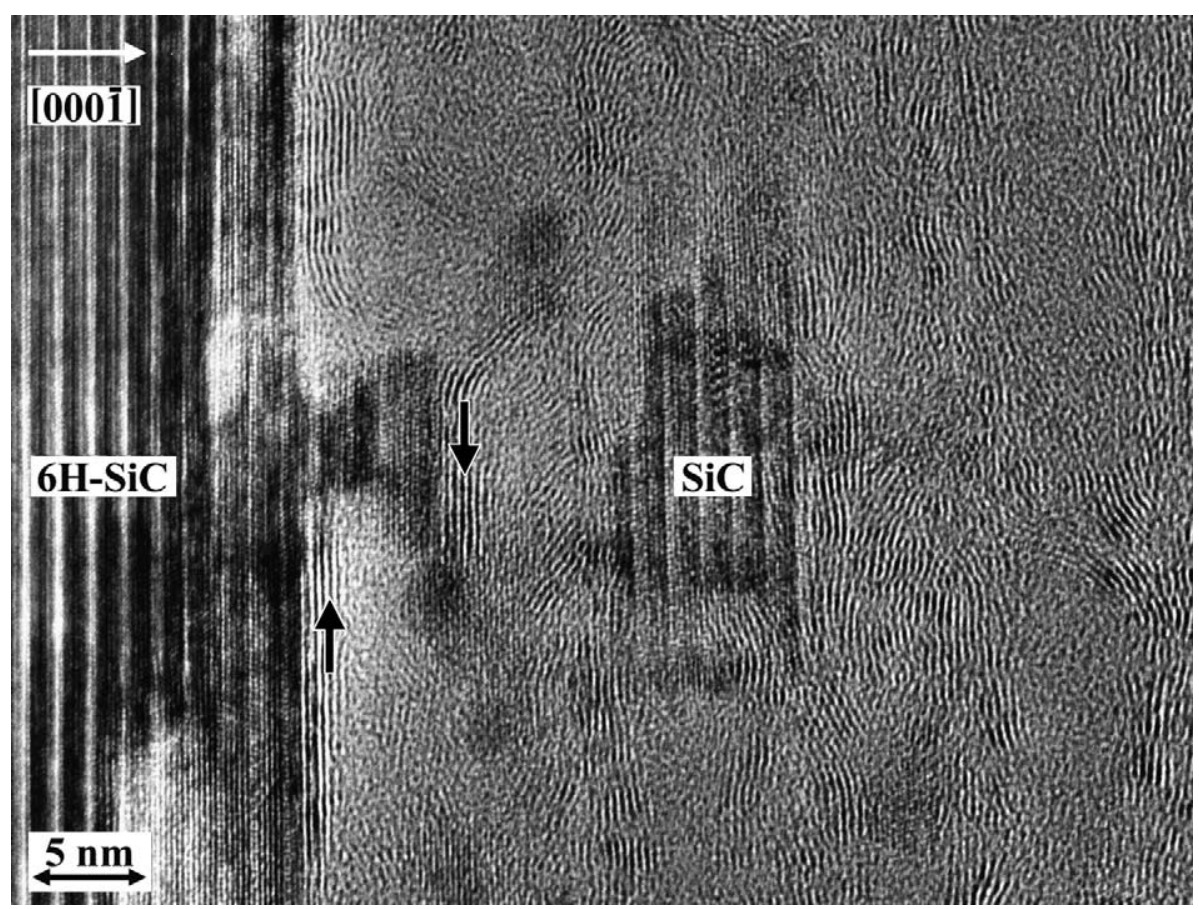

Fig. 2. Pt-enhanced disintegration of $6 \mathrm{H}-\mathrm{SiC}$ yielding to both the cleaving of the $\mathrm{SiC}$ interface and the formation of graphitic lamellae being nearly parallely aligned to the $(000 \overline{6})$ plane of $6 \mathrm{H}-\mathrm{SiC}$. Arrows represent the graphitic lamellae penetrating into $(000 \overline{6})$ planes of $6 \mathrm{H}-\mathrm{SiC}$.

can be generated (Eq. (2)) and finally precipitated near the $\mathrm{SiC}$ surface.

$x \mathrm{Pt}+y \mathrm{Si} \rightarrow \mathrm{Pt}_{x} \mathrm{Si}_{y}$

Summarising both steps yields Eq. (3), the reaction between $\mathrm{Pt}$ and $\mathrm{SiC}$ forming silicide and carbon.

$x \mathrm{Pt}+y \mathrm{SiC} \rightarrow \mathrm{Pt}_{x} \mathrm{Si}_{y}+y \mathrm{C}$

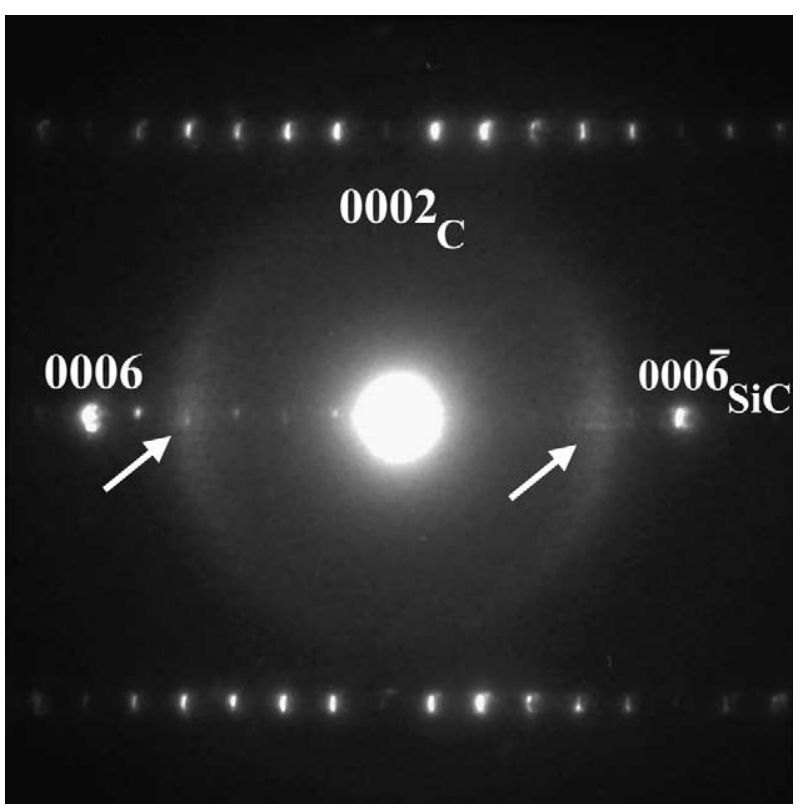

Fig. 3. Diffraction pattern from reaction layer and $6 \mathrm{H}-\mathrm{SiC}$ with arrows marking widened arcs in the 0002 diffraction ring of the graphene sheets within the layer (specimen of Pt-coated $6 \mathrm{H}-\mathrm{SiC}$ and borosilicate glass).
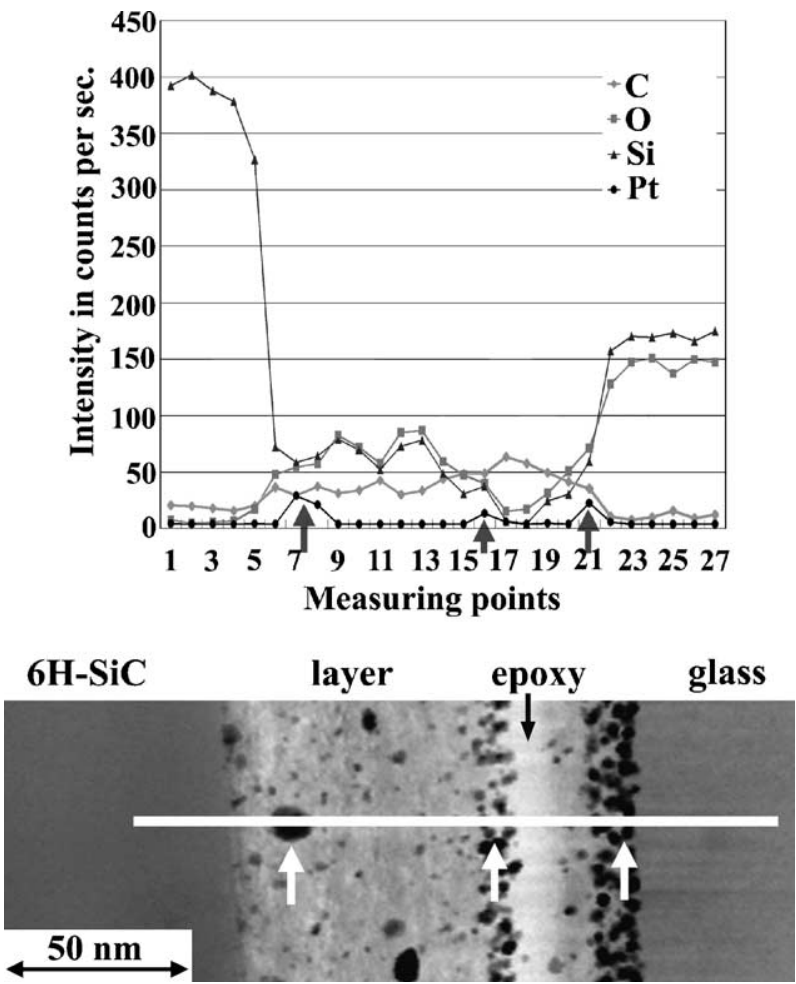

Fig. 4. EDX spectroscopy profiles recorded along the line marked in the STEM bright-field image, inserted below; arrows point to Pt-enrichment in particles. The thin epoxy region within the reaction layer is a preparation effect. 


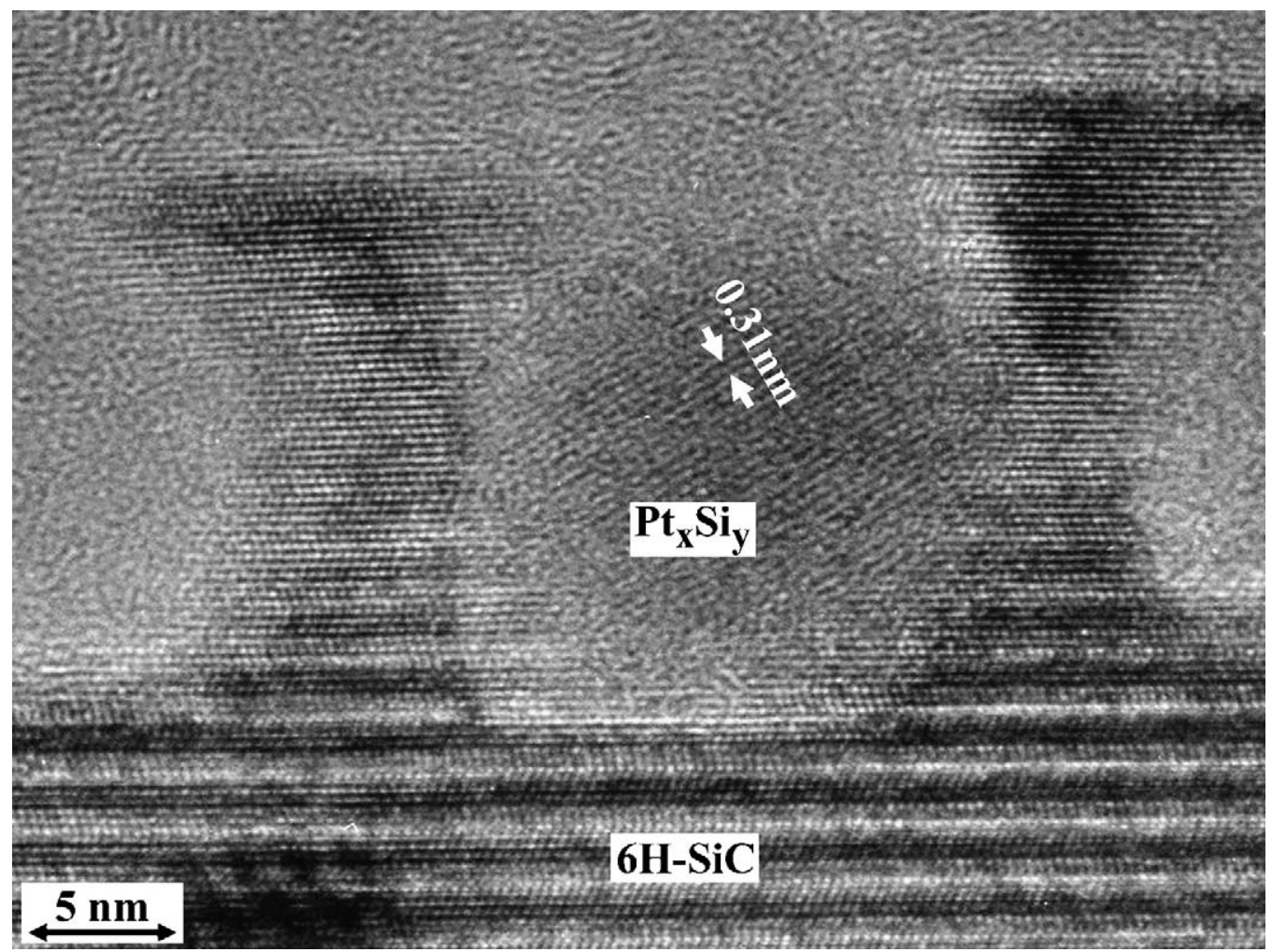

Fig. 5. Particle of $\mathrm{Pt}_{x} \mathrm{Si}_{y}$ in a trough of the $6 \mathrm{H}-\mathrm{SiC}$ indicating reaction processes between $\mathrm{SiC}$ and $\mathrm{Pt}$.

Fig. 5 shows details of the formation of platinum silicide at the attacked silicon carbide surface. Within a trough of the $\mathrm{SiC}$ (excavated by the reactions with the platinum), a particle of platinum silicide can be seen. It shows lattice fringes with a distance of $0.31 \mathrm{~nm}$, which does not correspond to any lattice spacings of elemental platinum as demonstrated in Table 1, but can be attributed to any of the platinum silicides $\mathrm{PtSi}, \mathrm{Pt}_{2} \mathrm{Si}$, or $\mathrm{Pt}_{12} \mathrm{Si}_{5}$, which is also shown in Table 1 . First nanoanalytical measurements via ELNES in correspondence with quantum-chemical calculations give hints to a preference of the silicide $\mathrm{Pt}_{2} \mathrm{Si}$ [30]. This would also be in agreement with the observation that the presence of $\mathrm{C}$ in the $\mathrm{Pt}-\mathrm{Si}-\mathrm{C}$ system (as in our case) favours the formation of metal-rich silicides [31].

\subsubsection{Graphitisation mechanisms}

To exclude possible influences of glass constituents on the Pt-enhanced graphitisation additional specimens were made by heat-treatment of Pt-coated $6 \mathrm{H}-\mathrm{SiC}$ at $977^{\circ} \mathrm{C}$ in $\mathrm{Ar}$ (partial pressure of oxygen about $10^{-13} \mathrm{~Pa}$ ) without a borosilicate glass matrix. Fig. 6 shows details of the interfacial reactions of these specimens. As indicated by arrows, silicide particles grown into the silicon carbide can be detected at the wafer surface. However, as the most interesting feature, atomic planes of graphite, aligned parallel to the particle surface, can clearly be seen at the silicide surface being opposite to the $\mathrm{SiC}$, on the left of the upper part of Fig. 6. Thus, the silicide formation at the interface to the $\mathrm{SiC}$ is coupled with the generation of carbon which possibly diffuses through the silicide to the opposite particle surface, where it is precipitated as graphitic carbon.

These findings are strong hints to a mechanism denoted as metal-mediated graphitisation [26] corresponding to the metal-mediated crystallisation of silicon and germanium [26,37-39]. In these cases, not only metals act as mediating agents but also their compounds like silicides. Thus, e.g.

Table 1

Interplanar distances $\mathrm{d}$ of $\mathrm{Pt}$ and of the silicides $\mathrm{Pt}_{3} \mathrm{Si}_{2} \mathrm{Pt}_{12} \mathrm{Si}_{5}, \mathrm{Pt}_{2} \mathrm{Si}$, and $\mathrm{PtSi}$ with those values marked, which correspond to the measured distance of $0.31 \mathrm{~nm}$

\begin{tabular}{llllllllll}
\hline $\mathrm{Pt}[32]$ & $\mathrm{Cubic}$ & $\mathrm{Pt}_{3} \mathrm{Si}[33]$ & $\mathrm{Cubic}$ & $\mathrm{Pt}_{12} \mathrm{Si}_{5}[34]$ & Tetragonal & $\mathrm{Pt}_{2} \mathrm{Si}[35]$ & Tetragonal & PtSi [36] & Ortho-rhombic \\
\hline $\mathrm{d}(\mathrm{nm})$ & $(h k l)$ & $\mathrm{d}(\mathrm{nm})$ & $(h k l)$ & $\mathrm{d}(\mathrm{nm})$ & $(h k l)$ & $\mathrm{d}(\mathrm{nm})$ & $(h k l)$ & $\mathrm{d}(\mathrm{nm})$ & $(h k l)$ \\
\hline 0.227 & $(111)$ & 0.274 & $(101)$ & 0.307 & $(321)$ & 0.329 & $(101)$ & 0.307 & $(011)$ \\
0.196 & $(002)$ & 0.224 & $(111)$ & 0.299 & $(420)$ & 0.298 & $(002)$ & 0.302 & $(110)$ \\
0.139 & $(202)$ & 0.194 & $(002)$ & 0.279 & $(411)$ & 0.279 & $(110)$ & 0.296 & $(002)$ \\
\hline
\end{tabular}




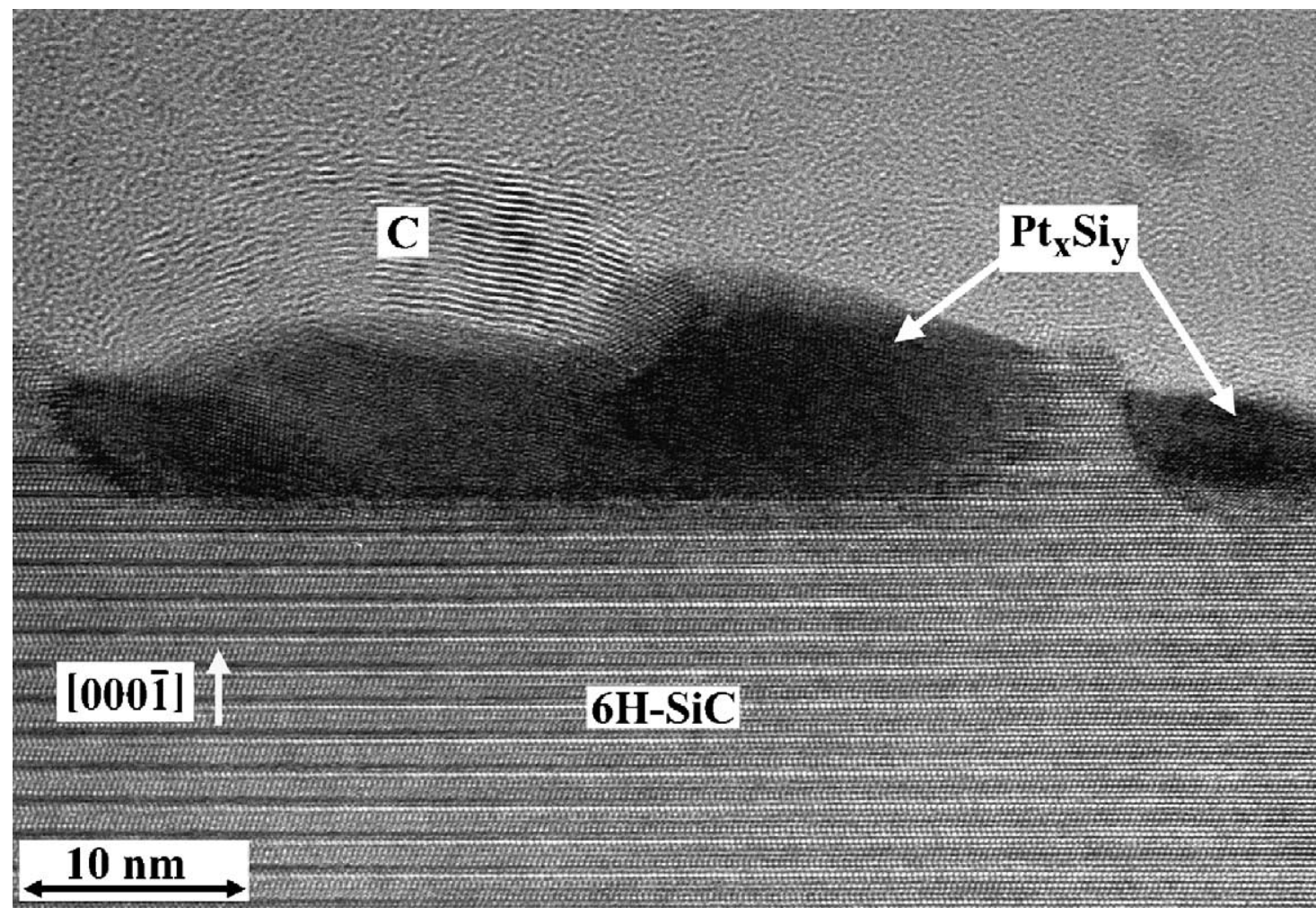

Fig. 6. Reaction zone in annealed, Pt-coated $6 \mathrm{H}-\mathrm{SiC}$ (without glass matrix) showing silicide particles, which were grown into the $6 \mathrm{H}-\mathrm{SiC}$. Note the graphitic carbon precipitated at the particle interface opposite to that with the $\mathrm{SiC}$ (above epoxy).

the silicide $\mathrm{NiSi}_{2}$ mediates the crystallisation of amorphous silicon [39]. This mechanism of crystallisation is supposed to be based on both (i) dominant diffusion of nickel atoms through the silicide and (ii) silicide disintegration. At the interface to the crystalline silicon, the silicide $\mathrm{NiSi}_{2}$ disintegrates producing nickel and silicon. The silicon atoms then arrange to form the crystalline silicon lattice, whereas the nickel atoms diffuse to the opposite interface between the silicide and the amorphous silicon with re-forming of the silicide $\mathrm{NiSi}_{2}$.

The driving force for the phase transformation is the reduction of the free energy associated with the transformation of metastable amorphous silicon into stable crystalline silicon. In analogy, for the graphitisation being mediated by metals the amorphous carbon is considered to dissolve within the metal by diffusion, resulting in a supersaturation with respect to the more stable graphitic phase due to the higher free energy of the amorphous state. Subsequently, a nucleation of graphite can take place, with growth of graphite by diffusion of carbon through the metal [26]. Thus, in our case, the relative diffusivities of $\mathrm{Pt}, \mathrm{Si}$ and $\mathrm{C}$ through the silicide should be the key parameters, which determine the graphitisation kinetics. However, no data are currently known to the authors about this problem. Nevertheless, studies of diffusion couples of the system $\mathrm{Pt}-\mathrm{SiC}$ have shown the mobility of $\mathrm{Si}$ in $\mathrm{Pt}_{2} \mathrm{Si}$ to be somewhat higher than that of Pt [40]. Moreover, the carbon product of the reaction between $\mathrm{SiC}$ and $\mathrm{Pt}$ has been considered to be non-diffusing by assuming an uniform carbon activity of 1 . However, the difference in the chemical potential of amorphous carbon and graphitic carbon has to be taken into account as it represents the driving force for the diffusion of carbon from the amorphous to the graphitic phase.

This state of knowledge permits to suppose only a rough model of graphitisation as described below, comprising the formation of silicide at the interface between the particle and the silicon carbide as well as the disintegration of platinum silicide at the interface between the particle and the reaction layer (cf. Fig. 7, labelled 1). At the latter interface platinum atoms are formed by the silicide disintegration, which will

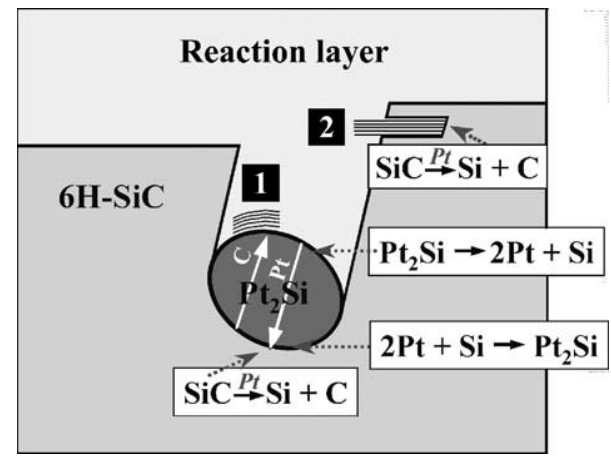

Fig. 7. Scheme of the graphitisation mechanisms being supposed to take place in sandwich structures of Pt-coated $6 \mathrm{H}-\mathrm{SiC}$ and borosilicate glass: 1-metal-mediated graphitisation; 2-Pt-catalysed stacking of graphitic lamellae (see text) 
diffuse through the silicide to the interface with the carbide. Here, $\mathrm{Si}$ and $\mathrm{C}$ are generated by the Pt-enhanced disintegration of the SiC. While Si atoms are consumed by the $\mathrm{Pt}_{2} \mathrm{Si}$ formation, $\mathrm{C}$ atoms diffuse through the silicide to the opposite interface with the reaction layer, where they precipitate to form graphitic lamellae. This suggestion of formation and disintegration of $\mathrm{Pt}_{2} \mathrm{Si}$ is also emphasised by elemental gradients, which have been found in $\mathrm{Pt} / 6 \mathrm{H}-\mathrm{SiC}$-reaction couples at the interfaces of $\mathrm{Pt}_{2} \mathrm{Si}$ to both the silicon carbide and the adjacent carbon layer [41]. $\mathrm{Pt}_{2} \mathrm{Si}$ regions near the $6 \mathrm{H}-\mathrm{SiC}$ has been described to be enriched in $\mathrm{Si}$, whereas those near the $\mathrm{C}$ layer are Pt-rich.

Complementary and prior to the above process, another graphitising mechanism can be assumed to be active in the carbon formed at the $\mathrm{SiC}$ interface. As shown schematically in Fig. 7, labelled 2, this mechanism presumably takes place parallel to the formation of silicides, that means, immediately after the Pt enhanced $\mathrm{SiC}$ disintegration. It is conceivable that $\mathrm{Pt}$ atoms affecting the disintegration of the $\mathrm{SiC}$ also catalyse the formation of the stacks of graphitic basal planes arising from the former $(000 \overline{6})$ planes of the $6 \mathrm{H}-\mathrm{SiC}$, which seem to be partly displaced by the expanding graphitic lamellae.

\subsubsection{Effect of oxidation processes}

Finally, the effect of oxygen, which diffuses from the borosilicate glass into the $\mathrm{SiC}$, has to be discussed. Fig. 8a presents a set of EEL spectra taken at points along the line in the STEM bright-field image on the right. From the up-

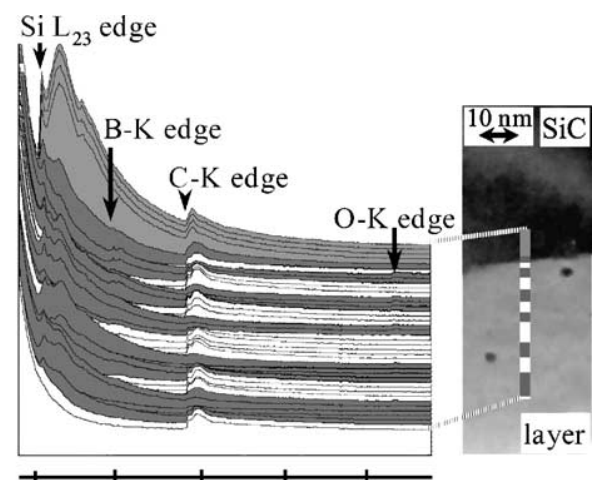

(a) $\begin{array}{rrrrr}100 & 200 & 300 & 400 & 500\end{array}$

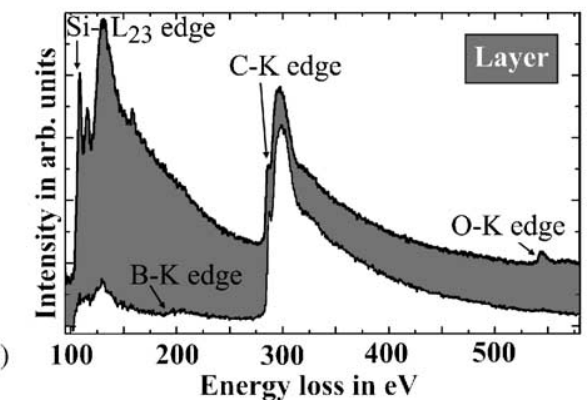

Fig. 8. (a) Set of electron energy loss spectra recorded along a line from the $6 \mathrm{H}-\mathrm{SiC}$ to the interlayer (inset: STEM bright-field image); (b) background-subtracted spectra within the layer. permost spectrum to the lowermost one, the energy loss near edge structures of both the $\mathrm{Si}-\mathrm{L}_{23}$ edge and the $\mathrm{C}-\mathrm{K}$ edge change, indicating a modification in the chemical bonding of the respective elements. Further on, an additional O-K edge occurs within the layer. The distinct B-K edges within the spectra from the layer hint to a diffusion of boron species from the glass to the $\mathrm{SiC}$.

The upper of the background-subtracted spectra recorded in the interlayer (Fig. 8b) appears quite similar to that of silica showing an onset at about $104 \mathrm{eV}$ and two distinctly split peaks at about 108.5 and $115.5 \mathrm{eV}$ [42]. This clearly demonstrates the high content of $\mathrm{SiO}_{2}$ in the reaction interlayer. Moreover, regions of high content of $\mathrm{SiO}_{2}$ (marked by dark grey filling) and those of low content of $\mathrm{SiO}_{2}$ alternate, whereas the reverse applies to the content of carbon. This is demonstrated in Fig. 8b showing background-subtracted spectra from both interlayer regions, normalised to the maximum intensity of the first plasmon peak after the $\mathrm{C}-\mathrm{K}$ edge. Corresponding to these analytical electron microscopy findings, HREM very clearly shows cellularly arranged lamellae of graphitic stackings, which are embedded into an amorphous $\mathrm{SiO}_{2}$ matrix (Fig. 9). Consequently, in sandwich structures with glass such oxidation effects have to be considered parallel to the reaction processes with platinum. Thus, at the interface to the $6 \mathrm{H}-\mathrm{SiC}$ at least two competing processes can take place-the reaction of $\mathrm{SiC}$ with oxygen;

$\mathrm{SiC}+\mathrm{O}_{2} \rightarrow \mathrm{SiO}_{2}+\mathrm{C}$

and that one with platinum discussed above (Eq. (3)).

Actually, the scenario at the silicon carbide surface will be determined by the kinetics of these interacting processes:

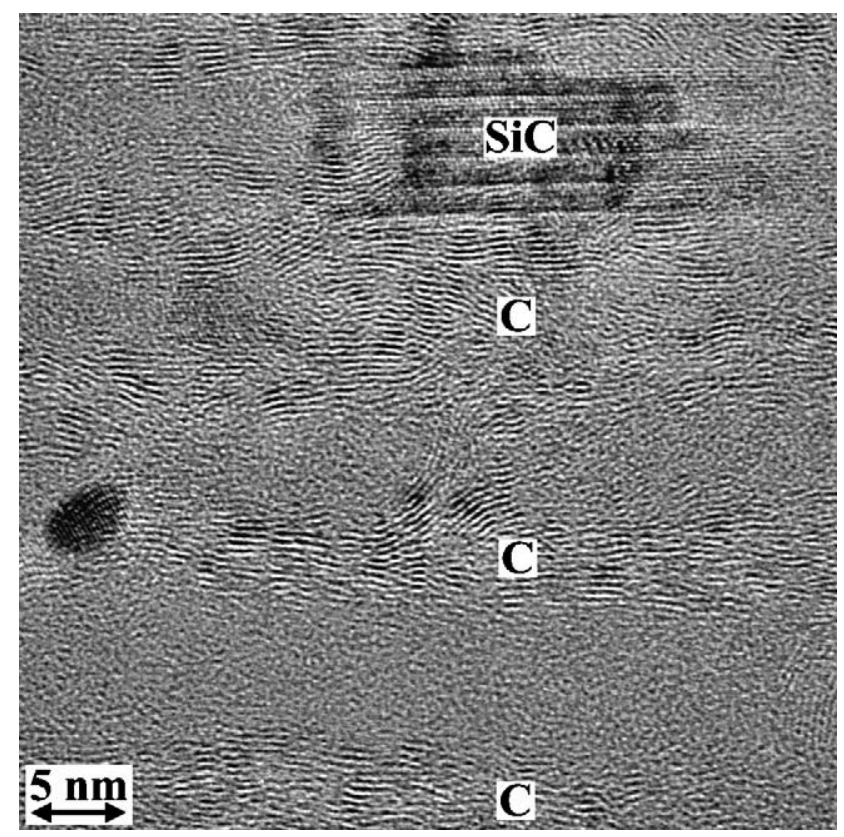

Fig. 9. HREM image of an interlayer region showing regularly arranged graphitic lamellae embedded into an amorphous matrix, a flake of $6 \mathrm{H}-\mathrm{SiC}$ (on the top), and a Pt-containing particle (on the left). 
If the oxidation prevails, then the products of Eq. (4) (silica and carbon) isolate the platinum or the platinum silicide, which has been already formed, and silicide particles are included into the reaction layer, as observed.

The formation of the alternate regions of silica and carbon within the reaction layer is assumed to be caused by the oxidation of the silicide particles themselves forming silica and platinum.

$\mathrm{Pt}_{x} \mathrm{Si}_{y}+\mathrm{O}_{2} \rightarrow y \mathrm{SiO}_{2}+x \mathrm{Pt}$

Thus, oxygen could initiate a cycling of the formation of silicides (Eqs. (2) or (3)) and that of platinum (Eq. (5)), which is equivalent to the decoupling of the formation of carbon (by the Pt-enhanced disintegration of SiC Eq. (1)) and the formation of silica (by the silicide oxidation Eq. (5)).

\section{Conclusions}

For the first time, the metal-mediated graphitisation was applied for structuring of interlayers in heat-treated silicon carbide/glass sandwiches. The microstructure and the nanochemistry of the reaction layers between carbide and glass were studied down to the atomic scale by HREM and spectroscopic techniques.

The carbon of the whole layer has been found to be significantly graphitised by the effect of platinum. Thus, the layer consists of a cellular net of lamellae of graphite basal planes embedded in a silica matrix. A number of

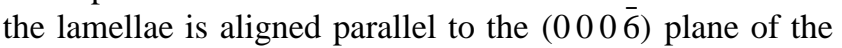
$6 \mathrm{H}-\mathrm{SiC}$ wafer resulting in a distinct texturisation of the carbon. The platinum is concentrated in particles located at the attacked surface of the SiC, within the layer, and especially at the interface to the glass. Both, the attacked $\mathrm{SiC}$ surface and the particles, which appear to consist of $\mathrm{Pt}_{x} \mathrm{Si}_{y}$ and especially of $\mathrm{Pt}_{2} \mathrm{Si}$, indicate a reaction between $\mathrm{Pt}$ and $\mathrm{SiC}$.

The procedure of layer formation has been shown to be very complex. It comprises processes induced by platinum as well as oxidation processes by oxygen diffusing from the glass to the $\mathrm{SiC}$. The first step of the reaction of $\mathrm{Pt}$ and $\mathrm{SiC}$ appears to be the Pt-enhanced disintegration of $\mathrm{SiC}$, which is indicated by graphitic stackings penetrating into the $(000 \overline{6})$ planes of the $6 \mathrm{H}-\mathrm{SiC}$. In this early stage of layer formation, the Pt-atoms could affect also the formation of graphitic lamellae from amorphous carbon being generated by the disintegration of SiC. Most of the platinum seems to react with silicon (the second product of the $\mathrm{SiC}$ disintegration) forming a silicide. These silicide particles mediate the graphitisation of the carbon products of both the reaction of $\mathrm{SiC}$ and $\mathrm{Pt}$ and the $\mathrm{SiC}$ oxidation. Thus, the observed enhancement of the graphitisation appears to be caused by a complex of combined effects of platinum and of a platinum silicide-mediated solution-precipitation mechanism.

\section{Acknowledgements}

The authors thank the Deutsche Forschungsgemeinschaft, Bonn for financial support. We owe special thanks to our colleagues Dr. A. Barthel and Dr. E. Pippel for valuable discussions.

\section{References}

[1] A.G. Evans, D.B. Marshall, Acta Metall. 37 (1989) 2567-2583.

[2] G. Grathwohl, M. Kuntz, E. Pippel, J. Woltersdorf, Phys. Stat. Sol. (a) 146 (1994) 393-414.

[3] G. Grathwohl, J. Woltersdorf, A. Hähnel, M. Kuntz, E. Pippel, R. Schneider, Bildung, Struktur, Nanochemie und Funktion von Grenzschichten in keramischen Faserverbundwerkstoffen, VDIVerlag Düsseldorf 1996, ISBN 3-18-345305-3.

[4] R. Naslain, O. Dugne, A. Guette, J. Sevely, C.R. Brosse, J.P. Rocher, J. Cotteret, J. Am. Ceram. Soc. 74 (1991) 2482-2488.

[5] E. Pippel, J. Woltersdorf, A. Hähnel, R. Schneider, Ceram. Trans. (Am. Ceram. Soc.) 57 (1995) 273-278.

[6] R.F. Cooper, K. Chyung, J. Mater. Sci. 22 (1987) 3148-3160.

[7] P.M. Benson, K.E. Spear, G.C. Pantano, Ceram. Eng. Sci. Proc. 9 (1988) 663-670.

[8] L.A. Bonney, R.F. Cooper, J. Am. Ceram. Soc. 73 (1990) 2916-2921.

[9] C. Ponthieu, M. Lancin, J. Thibault-Desseaux, Philos. Mag. A 62 (1990) 605-615.

[10] C. Ponthieu, C. Marhic, M. Lancin, N. Herbots, J. Mater. Sci. 29 (1994) 4535-4544.

[11] H. Shin, J. Am. Ceram. Soc. 78 (1995) 3153-3156.

[12] A. Kumar, K.M. Knowles, Acta Mater. 44 (1996) 2901-2921.

[13] A. Kumar, K.M. Knowles, J. Am. Ceram. Soc. 79 (1996) 2364-2374.

[14] R. Schneider, J. Woltersdorf, A. Röder, Microchim. Acta 125 (1997) 361-365.

[15] A. Hähnel, R. Schneider, E. Pippel, J. Woltersdorf, D. Suttor, Composites A 27 (1996) 685-690.

[16] E. Pippel, A. Hähnel, J. Woltersdorf, Silicates Industrials-Ceram. Sci. Technol. 64 (1999) 15-19.

[17] E. Fitzer, B. Kegel, Carbon 6 (1968) 433-446.

[18] D.B. Fischbach, in: P.L.D. Walker (Ed.), Chemistry and Physics of Carbon, Marcel Dekker, New York, 1971, vol. 7, pp. 1-105.

[19] C. Baraniecki, P.H. Pinchback, F.B. Pickering, Carbon 7 (1969) 213224.

[20] W. Weisweiler, N. Subramanian, B. Terwiesch, Carbon 9 (1971) $755-761$.

[21] A. Oberlin, J.P. Rouchy, Carbon 9 (1971) 39-46.

[22] A. Öya, M. Mochizuki, S. Ötani, I. Tomizuka, Carbon 17 (1979) 71-76.

[23] A. Öya, S. Ötani, Carbon 17 (1979) 131-137.

[24] D. Babonneau, T. Cabioc'h, A. Naudon, J.C. Girard, M.F. Denanot, Surf. Sci. 409 (1998) 358-371.

[25] O.P. Krivoruchko, A.N. Shmakov, V.I. Zaikovskii, Nucl. Inst. Meth. Phys. Res. A 470 (2001) 198-201.

[26] R. Sinclair, T. Itoh, R. Chin, Microsc. Microanal. 8 (2002) 288-304.

[27] A. Hähnel, E. Pippel, J. Woltersdorf, Cryst. Res. Technol. 35 (2000) 663-674.

[28] U. Kaiser, A. Chuvilin, W. Richter, Ultramicroscopy 76 (1999) 2137.

[29] J.S. Bow, R.W. Carpenter, M.J. Kim, J. Micros. Soc. Am. 2 (1996) 63-78.

[30] A. Hähnel, A. Barthel, J. Woltersdorf, Mater. Chem. Phys., in preparation.

[31] I. Shalish, C.E.M. de Oliveira, Y. Shapira, L. Burstein, M. Eizenberg, J. Appl. Phys. 88 (2000) 5724-5728.

[32] W.B. Pearson, A Handbook of Lattice Spacings and Structures of Metals and Alloys, vol. 4, Pergamon Press, Oxford, 1964. 
[33] R. Gohle, K. Schubert, Z. Metallkd. 55 (1964) 503-511.

[34] W. Gold, K. Schubert, Z. Kristallogr. 128 (1969) 406-413.

[35] R.P. Ram, S. Bhan, Z. Metallkd. 69 (1978) 524-529.

[36] K. Goeransson, I. Engstroem, B. Nolaeng, J. Alloys Compd. 219 (1995) 107-110.

[37] T.J. Konno, R. Sinclair, Philos. Mag. B 71 (1995) 179-199.

[38] T.J. Konno, R. Sinclair, Philos. Mag. B 71 (1995) 163-178.
[39] C. Hayzelden, J.L. Batstone, J. Appl. Phys. 73 (1993) 8279-8289.

[40] M.R. Rijnders, A.A. Kodentsov, J.A. van Beek, J. van den Akker, F.J.J. van Loo, Solid State Ionics 95 (1997) 51-59.

[41] R.W. Carpenter, J.S. Bow, M.J. Kim, K. Das Chowdhury, W. Braue, Microsc. Microanal. Microstruct. 6 (1995) 587-599.

[42] R. Schneider, J. Woltersdorf, O. Lichtenberger, J. Phys. D: Appl. Phys. 29 (1996) 1709-1715. 